\title{
IDENTIFIKASI PENYAKIT PADA DAUN TOMAT BERDASARKAN FITUR WARNA DAN TEKSTUR
}

\author{
Mungki Astiningrum ${ }^{1}$, Putra Prima Arhandi ${ }^{2}$, Nabilla Aqmarina Ariditya ${ }^{3}$ \\ 1,2,3 Jurusan Teknologi Informasi, Politeknik Negeri Malang \\ ${ }^{1}$ mungki.polinema@gmail.com, ${ }^{2}$ putraprima@ polinema.ac.id, ${ }^{3}$ nabilla.aqmarina@ gmail.com
}

\begin{abstract}
Abstrak
Tomat adalah salah satu buah yang banyak dikonsumsi oleh masyarakat Indonesia. Akan tetapi, produksi tomat tidak diimbangi dengan budidaya yang baik sehingga daun tomat terserang penyakit. Di Indonesia, penyakit utama yang menyerang daun tomat yaitu busuk daun dan bercak bakteri. Busuk daun mengakibatkan pertumbuhan tanaman tomat terhambat dan bercak bakteri mengakibatkan kualitas tanaman tomat kurang baik. Saat ini, identifikasi penyakit masih dilakukan secara manual dengan penglihatan manusia. Cara ini membuat petani menggunakan obat yang salah dalam menyembuhkan penyakit daun tomat. Teknologi pengolahan citra digital dapat digunakan untuk mengetahui kondisi daun tomat yang terserang penyakit dengan mudah. Penelitian ini bertujuan untuk merancang sistem identifikasi penyakit pada daun tomat dengan menggunakan $R G B$ sebagai fitur ekstraksi warna dan Gray Level Co-Occurance Matrix (GLCM) sebagai fitur ekstraksi tekstur. Hasil dari sistem identifikasi penyakit pada daun tomat adalah penentuan label Sehat, Bercak Bakteri, dan Busuk Daun. Tingkat akurasi penelitian ini adalah $92,89 \%$ pada nilai $\mathrm{k}=1$ dengan menggunakan metode $K$-Nearest Neighbor $(K N N)$.
\end{abstract}

Kata kunci : daun tomat; bercak bakteri; busuk daun; RGB; GLCM, KNN).

\section{Pendahuluan}

Tomat merupakan tanaman yang banyak dibudidayakan di Indonesia. Buah tomat dikenal sebagai sumber vitamin A dan $\mathrm{C}$ yang sangat baik [9]. Seiring dengan bertambahnya jumlah penduduk dan meningkatnya kesadaran masyarakat akan pentingnya kesehatan, permintaan tomat diprediksi akan terus mengalami peningkatan. Hingga saat ini peningkatan produksi tomat masih terkendala oleh faktor penyakit tanaman. Penyakit utama pada tanaman tomat pada rata-rata pertanaman tomat di Indonesia adalah penyakit busuk daun [10]. Untuk membedakan penyakit daun bercak daun dan busuk daun masih dilakukan secara kasat mata, Akibatnya, petani sering keliru menggunakan obat pada saat mengendalikan penyakit sehingga mengakibatkan kerugian atau kerusakan tanaman.

Saat ini, teknologi pengolahan citra digital berkembang sangat pesat. Berbagai aplikasi pengolahan citra baik dalam bentuk piranti keras maupun piranti lunak tersedia dengan berbagai fitur sebagai bentuk keunggulannya. Salah satu teknologi pengolahan citra adalah computer vision atau machine vision. Pada hakikatnya, computer vision mencoba meniru cara kerja sistem visual manusia (human vision). Computer vision bertujuan untuk mengkomputerisasi penglihatan manusia atau dengan kata lain membuat citra digital dari citra sebenarnya (sesuai dengan penglihatan manusia) [6].

Berdasarkan permasalahan diatas, diperlukan sistem yang dapat membantu petani tomat dalam mengidentifikasi penyakit yang menyerang daun tomat, salah satunya dengan menggunakan pengolahan citra digital. Dengan menggunakan pengolahan citra digital membuat komputer dapat mendeteksi spot pada daun tomat menggunakan ekstraksi fitur warna dan tekstur pada citra daun tomat. Dengan mengklasifikasikan penyakit bercak bakteri dan busuk daun, diharapkan dapat membantu petani tomat dalam melakukan pencegahan terhadap penyakit daun tomat pada perawatan selanjutnya.

\section{Tinjauan Pustaka}

\subsection{Tanaman Tomat}

Tomat yang didomestifikasikan pertama kali ada di Meksiko, yakni tomat cherry (Lycopersicium esculentum var cerasiformae). Setelah itu, tomat menyebar ke negara-negara Eropa, sleanjutnya menyebar ke Cina, Asia, termasuk ke Indonesia.

Di Indonesia tanaman ini mulai dibudidayakan secara komersial pada tahun 1988 setelah adanya introduksi varietas hibrida dari Taiwan yakni Precious 375. Tanaman tomat juga memiliki banyak ragam bentuk dan tipe buah. Bentuk dan ukuran buahnya bervariasi, mulai dari sebesar kelereng sampai sebesar apel, berbentuk gepeng, bulat, lonjong, kotak, hingga Panjang. [8].

\subsection{Tomat Sayur}

Tomat biasa atau tomat sayur memiliki bentuk buahnya bulat pipih, bentuknya tidak teratur, sedikit beralur terutama di dekat tangkai. Jenis tomat ini 
cocok ditanam didaerah dataran rendah. Tomat biasa inilah yang sering ditemukan di pasar-pasar lokal [1].

\subsection{Citra RGB}

Citra berwarna RGB adalah citra yang memiliki 3 level/channel warna direpresntasikan dengan resolusi citra 3 dimensi terdiri dari Red, Green, dan Blue. Pada identifikasi penyakit daun tomat, fitur warna yang digunakan adalah ekstraksi warna RGB. Nilai yang diperoleh dari ekstraksi warna RGB berupa normalisasi RGB. Persamaan normalisasi RGB adalah sebagai berikut:

Melakukan normalisasi nilai RGB adalah sebagai berikut :

$$
\begin{aligned}
& \text { Normalisasi Red }(\mathrm{R})=\frac{R}{R+G+B} \\
& \text { Normalisasi Green }(\mathrm{G})=\frac{G}{R+G+B} \\
& \text { Normalisasi Blue }(\mathrm{B})=\frac{B}{R+G+B}
\end{aligned}
$$

\subsection{Citra Grayscale}

Citra grayscale adalah matriks data yang nilainilainya mewakili intensitas setiap piksel berkisar antara 0 sampai dengan 255. Setiap piksel membutuhkan 8 bit memori.[5]. Persamaan untuk konversi ke citra grayscale adalah sebagai berikut:

$$
\text { Average }=\mathrm{R}+\mathrm{G}+\mathrm{B} / 3
$$

\subsection{Gray Level Co-occurance Matrix}

GLCM (Gray Level Co-occurrence Matrix) adalah matriks yang merepresentasikan hubungan ketetanggan antarpiksel dalam citra pada berbagai arah orientasi $\boldsymbol{\theta} 0^{\circ}, 45^{\circ}, 90^{\circ}$, dan $135^{\circ}$ dan jarak $\mathbf{d}$. Matriks GLCM dari suatu citra $f(x, y)$ adalah matriks dua dimensi $(x, y)$ dimana setiap elemen dari matriks mewakili probabilitas terjadinya bersama tingkat intensitas $x$ dan $y$ pada jarak $\boldsymbol{d}$ tertentu dan sudut $\boldsymbol{\theta}$. Di dalam satu arah, ada satu matriks GLCM untuk masing-masing nilai yang dipilih dari jarak $\boldsymbol{d}$ dan sudut $\boldsymbol{\theta}$. [3]

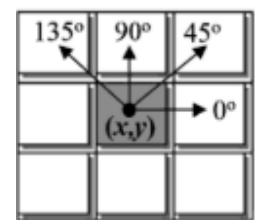

Gambar 1. Matriks GLCM dengan arah $0^{\circ}, 45^{\circ}, 90^{\circ}$, dan $135^{\circ}$

Persamaan pada ciri ekstraksi GLCM menurut [7] yang digunakan untuk identifikasi penyakit pada daun tomat ini adalah:

1. Energi

$$
f_{1}=\sum_{i=0}^{K-1} \sum_{j=0}^{K-1} P i j^{2}
$$

2. Kontras

$$
f_{2}=\sum_{i=0}^{K-1} \sum_{j=0}^{K-1}(i-j)^{2} P(i, j)^{2}
$$

3. Homogenitas

$$
f_{3}=\sum_{i=0}^{K-1} \sum_{j=0}^{K-1} \frac{P(i, j)}{1+|i-j|}
$$

4. Korelasi

$$
f_{4}=\sum_{i=0}^{K-1} \sum_{j=0}^{K-1} \frac{\left(\mathrm{i}-m_{r}\right)\left(\mathrm{j}-m_{c}\right) P(i, j)}{\sigma_{r} \sigma_{c}}
$$

\subsection{K-Nearest Neighbor}

Algoritma KNN (K-Nearest Neighbor) adalah sebuah metode untuk melakukan klasifikasi terhadap objek berdasarkan data pembelajaran yang jaraknya paling dekat dengan objek tersebut. K-Nearest Neighbor termasuk dalam algoritma supervised learning dimana hasil dari instance yang baru diklasifikasikan berdasarkan mayoritas dari kategori k-tetangga terdekat.

Pada fase training, algoritma ini hanya melakukan penyimpanan vektor-vektor fitur \& klasifikasi data training sampel. Pada fase klasifikasi, fitur-fitur yang sama dihitung untuk testing data (klasifikasinya belum diketahui).

Untuk mendefinisikan jarak antara dua titik yaitu titik pada data training (x) \& titik pada data testing (y) maka dipakai rumus Eucliden, seperti yang ditunjukkan pada persamaan:

$$
d(x, y)=\sqrt{\sum_{k}^{n}\left(x_{i}-y_{i}\right)^{2}}
$$

\section{Metodologi Penelitian}

\subsection{Metode Pengumpulan Data}

Jenis data yang digunakan untuk penelitian ini adalah kuantitatif, yaitu data yang berupa angka. Data yang digunakan untuk penelitian adalah nilai dari proses pada sistem berdasarkan fitur ekstraksi pada daun tomat sehat, daun tomat bercak bakteri, dan daun tomat busuk daun. Sedangkan, sumber data, diperoleh dari studi pustaka, pengambilan dataset dari website PlantVillage[4], dan observasi.

\subsection{Metode Pengembangan Sistem}

Pada penelitian ini, metode pengembangan sistem yang digunakan adalah Metode waterfall. Metode waterfall ini melakukan pendekatan secara sistematis dan urut mulai dari level kebutuhan sistem lalu menuju ke tahap analisis, desain, coding, testing/verification, dan maintenance. Menurut Pressman dan Sommerville tahun 2010 [2], metode ini terdiri dari beberapa langkah, seperti yang ditunjukkan pada gambar berikut:

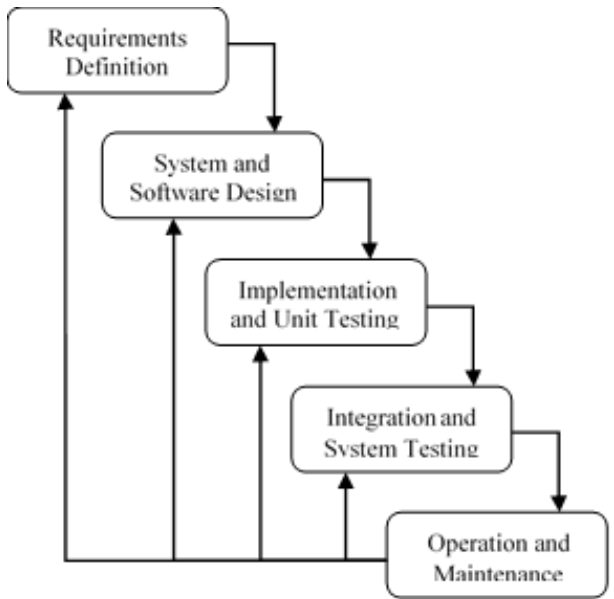

Gambar 2. Metode Waterfall 


\section{Analisis dan Perancangan}

\subsection{Gambaran Umum Aplikasi}

Aplikasi identifikasi penyakit pada daun tomat berdasarkan fitur warna dan tekstur ini menggunakan metode K-Nearest Neighbor. Aplikasi ini dikembangkan berbasis desktop menggunakan bahasa pemrograman C\#. Citra daun tomat yang digunakan sebagai objek penelitian adalah daun tomat sehat, bercak bakteri, dan busuk daun. Pada aplikasi ini, sistem klasifikasi penyakit pada daun tomat secara umum memiliki tiga proses yaitu proses cropping citra, proses ekstraksi fitur warna menggunakan RGB, proses ekstraksi fitur tekstur menggunakan GLCM, proses training, dan proses testing menggunakan klasifikasi KNN. Tahap awal dari aplikasi ini adalah input citra daun tomat yang akan diteliti. Selanjutnya dilakukan esktraksi fitur warna dan tekstur pada citra daun tomat. Tahap akhir yaitu klasifikasi KNN akan bekerja untuk mendapatkan hasil identifikasi penyakit pada daun tomat tersebut.

\subsection{Diagram Alur Sistem}

Berikut merupakan diagram alur proses training dan testing pada sistem identifikasi penyakit pada daun tomat berdasarkan fitur warna dan tekstur:

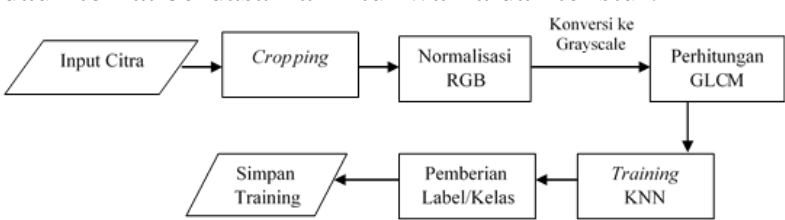

Gambar 3. Diagram alur training

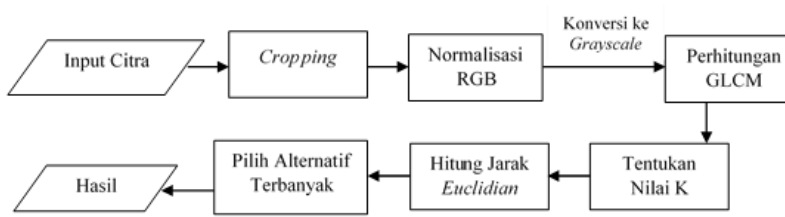

Gambar 4. Diagram alur testing

\section{Hasil dan Pembahasan}

Penggunaan sistem identifikasi penyakit pada daun tomat berdasarkan fitur warna dan tekstur menggunakan klasifikasi KNN seluruhnya dapat ditunjukkan pada langkah-langkah dibawah ini:

1. Melakukan pengambilan gambar pada citra daun tomat.

2. Memindahkan foto citra daun tomat ke desktop.

3. Input citra daun tomat yang akan diproses ke dalam sistem.

4. Cropping pada citra input daun tomat menjadi 100x100 piksel.

5. Melakukan ekstraksi warna RGB.

6. Melakukan konversi citra RGB menjadi citra grayscale.

7. Melakukan ekstraksi tekstur GLCM pada ciri energi, kontras, homogenitas, dan korelasi.
8. Input nilai ekstraksi warna RGB dan ekstraksi tekstur GLCM ke dalam database untuk dijadikan sebagai dataset.

9. Pada tahap training, dilakukan normalisasi pada dataset.

10. Menyimpan nilai hasil normalisasi dataset ke dalam database.

11. Pada tahap testing, dilakukan perhitungan Euclidian distance antara data training dan data testing.

12. Melakukan sorting pada data hasil perhitungan Euclidian distance.

13. Melakukan uji coba pada nilai $\mathrm{k}=1$.

14. Menentukan kelas/label berdasarkan k.

\section{Pengujian Akurasi}

Pengujian pada nilai $\mathrm{k}=1$ digunakan untuk mencari nilai terbaik yang akan digunakan. Pengujian dilakukan dengan perhitungan akurasi menggunakan confusion matrix. Hasil yang diperoleh berupa tingkat akurasi dari masing-masing pengujian nilai k. berikut ini adalah hasil dari pengujian tersebut:

TABEL I. CONFUSION MATRIX SEMUA KELAS

\begin{tabular}{|c|c|c|c|}
\hline \multirow{2}{*}{ Predictive } & \multicolumn{3}{|c|}{ Actual } \\
\cline { 2 - 4 } & Sehat & $\begin{array}{c}\text { Bercak } \\
\text { Bakteri }\end{array}$ & Busuk Daun \\
\hline Sehat & 48 & 1 & 0 \\
\hline $\begin{array}{c}\text { Bercak } \\
\text { Bakteri }\end{array}$ & 2 & 44 & 8 \\
\hline Busuk Daun & 0 & 5 & 42 \\
\hline
\end{tabular}

TABEL II. CONFUSION MATRIX MASING-MASING KELAS

\begin{tabular}{|c|c|c|c|c|}
\hline Kelas & \multicolumn{4}{|l|}{ Matrix } \\
\hline \multirow[t]{4}{*}{ Sehat } & & & \multicolumn{2}{|c|}{ Actual } \\
\hline & & & + & - \\
\hline & \multirow{2}{*}{ Predictive } & + & 48 & 1 \\
\hline & & - & 2 & 99 \\
\hline \multirow{4}{*}{$\begin{array}{l}\text { Bercak } \\
\text { Bakteri }\end{array}$} & & & \multicolumn{2}{|c|}{ Actual } \\
\hline & & & + & - \\
\hline & \multirow[t]{2}{*}{ Predictive } & + & 44 & 10 \\
\hline & & - & 6 & 90 \\
\hline \multirow{2}{*}{$\begin{array}{l}\text { Busuk } \\
\text { Daun }\end{array}$} & \multicolumn{4}{|c|}{ Actual } \\
\hline & & & & - \\
\hline
\end{tabular}

\begin{tabular}{|l|l|l|l|l|}
\hline \multicolumn{2}{|l|}{ Kelas } & \multicolumn{3}{l|}{ Matrix } \\
\hline $\begin{array}{l}\text { Busuk } \\
\text { Daun }\end{array}$ & \multicolumn{2}{l|}{} & \multicolumn{2}{l|}{ Actual } \\
\cline { 3 - 5 } & \multicolumn{2}{|l|}{} & + & - \\
\cline { 2 - 5 } & \multirow{2}{*}{ Predictive } & + & 42 & 5 \\
\cline { 3 - 5 } & & - & 8 & 95 \\
\hline
\end{tabular}

Pengujian terhadap sistem identifikasi penyakit pada daun tomat berdasarkan fitur warna dan tekstur dilakukan dengan perhitungan akurasi menggunakan 
confusion matrix. Berdasarkan nilai $\mathrm{k}=1$ yang telah dilakukan uji coba, secara keseluruhan rata-rata tingkat akurasi pada setiap kelas ditunjukkan pada Tabel III. berikut ini:

TABEL III. RATA-RATA AKURASI DENGAN NILAI $\mathrm{K}=1$.

\begin{tabular}{|c|c|}
\hline \multicolumn{2}{|c|}{$K=1$} \\
\hline Sehat & $98 \%$ \\
\hline $\begin{array}{l}\text { Bercak } \\
\text { Bakteri }\end{array}$ & $89,33 \%$ \\
\hline Busuk Daun & $91,33 \%$ \\
\hline \multicolumn{2}{|c|}{$K=1$} \\
\hline Rata-Rata & $92,89 \%$ \\
\hline
\end{tabular}

Pada Tabel III, ditampilkan rata-rata akurasi pada setiap kelas yang telah dilakukan uji coba dengan nilai $\mathrm{k}=1$. Rata-rata akurasi dari setiap kelas yaitu sebesar 92,89\% dengan persentase akurasi pada kelas Sehat yaitu sebesar 98\%, akurasi pada kelas Bercak Bakteri sebesar 89,33\%, dan akurasi pada kelas Busuk Daun sebesar 91,33\%. Sehingga dapat disimpulkan bahwa, hasil akurasi dalam pengujian sistem identifikasi penyakit pada daun tomat berdasarkan fitur warna dan tekstur menggunakan akurasi confusion matrix dan uji coba nilai $\mathrm{k}$ pada klasifikasi KNN adalah pada nilai $\mathrm{k}=1$ dengan tingkat akurasi sebesar 92,89\%.

\section{Kesimpulan}

Berdasarkan penelitian ini, maka dapat disimpulkan bahwa implementasi sistem identifikasi penyakit pada daun tomat dapat dilakukan dengan menggunakan ekstraksi warna RGB, ekstraksi fitur tekstur Gray Level Co-occurance Matrix (GLCM) dan klasifikasi K-Nearest Neighbor (KNN). Dataset yang digunakan pada penelitian ini berjumlah 750 citra daun tomat yang terdiri dari 600 citra daun untuk proses training dan 150 citra daun untuk proses testing. Nilai $\mathrm{k}$ yang diuji pada klasifikasi KNN nilai 1. Nilai $\mathrm{k}$ terbaik yang diperoleh setelah dilakukan pengujian menggunakan akurasi pada confusion matrix adalah nilai $\mathrm{k}=1$ dengan hasil akurasi sebesar $92,89 \%$.

\section{Daftar Pustaka}

[1] Bernardinus T.W.W, 2008. Bertanam Tomat. PT AgroMedia Pustaka : Tangerang

[2] Ian Sommerville, "Software Engineering (Rekayasa Perangkat Lunak)", 6th ed, Jakarta : Erlangga, 2003.

[3] Kurniawan Ilhass U.A, Aripin, "Identifikasi Penyakit Busuk Lunak Batang Pada Buah Naga Merah (Hylocereuss Polyrhizus) Dengan Ekstrasi Ciri GLCM Dan Klasifikasi K-NN", Universitas Dian Nurswantoro, 2017

[4] PlantDisease Dataset [online]. https://www.kaggle.com/emmarex/plantdisease. Diakses pada tanggal 24 November 2018 pukul 20.13 WIB

[5] Pulung N.A., T.Sutojo, Muljono, 2017. Pengolahan Citra Digital. Penerbit Andi : Yogyakarta

[6] Putra Darma, 2010. Pengolahan Citra Digital. Penerbit Andi: Yogyakarta

[7] Rafael C. Gonzales dan Richard E.Woods, Digital Image Processing; Third Edition. Chapter 11 : Representation and Description, s 830 -832. 2008. Pearson Education, US

[8] Rahmansyah D \& Nurul H, 2012.Tomat Unggul. Penebar Swadaya : Jakarta

[9] Wenner, B.Z.H, 2000. Importance of The Tomato. [online] http://www.agrisupportonline.com/Articles/imp ortance_of_the_tomato.htm. Diakses pada tanggal 26 November 2018 pukul 08.30 WIB

[10] Wiguna, G., Dkk, 2015. Respon Beberapa Galur Tomat (Lycopersicum esculentum Mill.) Terhadap Penyakit Busuk Daun (Phytophthora infestans (Mont.) de Bary). Jurnal Ilmu-ilmu Pertanian VOL . 11. NO. 2. 2015. HAL. 1-10 